\title{
The use of combination of zeolites to pursue integrated refined pyrolysis oil from kraft lignin
}

\author{
Fang Huang, Haoxi Ben, Shaobo Pan, Yunqiao Pu and Arthur Ragauskas*
}

\begin{abstract}
A mixture of $Y$ and $M$ type zeolites were applied to pyrolyze kraft softwood (SW) lignin with the objective of studying the combination effect of different types of zeolite on pyrolysis. The chemical structures of the subsequent pyrolysis oils were examined. Nuclear Magnetic Resonance (NMR) spectroscopy including ${ }^{13} \mathrm{C},{ }^{31} \mathrm{P}$ of phosphitylated bio-oils, Heteronuclear Single-Quantum Correlation (HSQC)-NMR, and Gel Permeation Chromatography (GPC) were used to characterize the pyrolysis oils. The yields of pyrolysis products (light oil, heavy oil and char) from the zeolites combination $\checkmark+M^{\prime}$ catalyzed pyrolysis ranged between the pyrolysis oil yields from zeolite $Y$ or $M$ catalyzed pyrolysis. ${ }^{31} \mathrm{P}$ NMR analysis of the phosphitylated bio-oils revealed that the mixture of ' $Y+M^{\prime}$ ' during pyrolysis could decrease the carboxyl groups by $84 \%$, which is close to the effect of the M zeolite. The yields of hydroxyl groups and other functional groups in the ' $Y+M^{\prime}$ generated bio-oil was between the individual $Y$ and $M$ generated oils. The molecular weight of the pyrolysis oil using a zeolite mixture of ' $Y+M^{\prime}$ was similar to the individual zeolite $Y$ assisted pyrolysis. These results show that the zeolite mixture of ' $Y+M$ ' manifests additive characteristics for pyrolysis.
\end{abstract}

Keywords: Zeolite combination, Pyrolysis, Kraft lignin

\section{Introduction}

Over the last century, worldwide energy consumption has increased rapidly, and the known petroleum resources are predicted to be consumed in less than fifty years at present rates of consumption [1,2]. Lignocellulosic biofuels are a promising fuel platform since substantial amounts of plant/wood residual biomass are readily available, with no competition for food resources and with relatively low environmental impact [3]. There is a vast potential supply of sustainable renewable biomass from forest and fallow lands throughout the world. Indeed, the United States alone has the ability to provide more than 1.3 billion dry tons annually to supply bio-refineries [4], which is enough to address approximately one-third of current demand for transportation fuels in an environmentally compatible manner [5].

Lignocellulosic biomass represents a renewable and carbon-neutral resource for the production of bio-fuels and bio-chemicals. Generally, lignocellulosic biomass contains around $35-50 \%$ of cellulose, which is a polymer of $\beta-(1,4)$ glucan with a degree of polymerization of $\sim 1000-15,000$

\footnotetext{
* Correspondence: arthur.ragauskas@chemistry.gatech.edu

School of Chemistry and Biochemistry, Institute of Paper Science and Technology, Georgia Institute of Technology, Atlanta, Georgia 30332, USA
}

[6]; 25-30\% of hemicellulose, which is a short-chain branched and substituted linear polymer of sugars with a degree of polymerization of $~ 70-200$; and another $15-30 \%$ of lignin which is a polymer derived from coniferyl, coumaryl, and sinapyl alcohols [2]. Cellulose in lignocellulosic biomass is now generally recognized as a major renewable resource for fuels and chemicals. However, lignin has received much less attention than plant polysaccharides as a resource for biofuels and is generally regarded as a low value compound. For example, large quantities of kraft lignin are produced from the pulp and paper industry that has been mainly used as an energy source in combustion processes and less than $5 \%$ of the world's supply has been used for other purposes [7]. Recently, lignin separation technology has been developed to recover and utilize lignin as resources of biofuels and chemicals [8]. The pyrolysis of lignin, including kraft lignin, is a promising approach to utilize this resource for fuels and aromatic chemicals $[9,10]$.

The chemical components of the bio-oils from lignin pyrolysis are very complex containing large amounts of aromatic structures $(\sim 40-70 \%)$, such as phenol, cresol and xylenol, substituted with methoxyl and aliphatic groups [11-14]. However, lignin pyrolysis oils cannot be used directly as fuel due to several unfavorable 
properties, such as high oxygen content, poor volatility, high acidity and viscosity, which significantly limit its usage $[15,16]$. Therefore, upgrading lignin-derived pyrolysis oil is needed so as to facilitate the generation of green diesel and/or gasoline.

Many researchers have examined the use of additives, including zeolite and metal salts to upgrade the properties of bio-oil during the pyrolysis of lignin. Mullen et al. [17] suggested that H-ZSM-5 zeolite could improve the depolymerization of lignin, and $\mathrm{CoO} / \mathrm{MoO}_{3}$ facilitated the production of aromatic hydrocarbons through a direct deoxygenation of methoxyphenol units. French et al. [18] found that transition metal substituted ZSM-5 zeolites could increase hydrocarbon yields during the pyrolysis of lignin. Zhao et al. [19] also suggested that zeolites could improve deoxygenation reactions during lignin pyrolysis. Different zeolites have different frameworks and pore sizes which influence pyrolysis product yields and structures. Our previous research studies have investigated the pyrolysis of kraft lignin with various zeolites, including Beta (BEA), Y (FAU), ZSM-5 (MFI), Mordenite (MOR) and Ferrierite (FER) zeolites [20]. The results indicated that the FAU (Y) and BEA (B) zeolites could significantly improve the cleavage of methoxyl-aromatic linkages and ether bonds in the lignin and yield a pyrolysis oil that has a 'gasoline' range molecular weight. The MFI (Z), FER $(\mathrm{F})$ and MOR (M) zeolites could more efficiently decompose the carboxyl groups in a bio-oil which reduces the acidity of pyrolysis oils and makes it more suitable for use as a biofuel after hydrotreatment. It's well known that different types of zeolite could exhibit different catalytic behavior during pyrolysis; however, as far as we know, there are no detailed reports of employing combinations of different types of zeolite to pursue enhanced deoxygenation during pyrolysis.

Based on our previous studies, different zeolites have different effects on the pyrolysis of kraft lignin. In this study, the combination of $\mathrm{Y}$ and $\mathrm{M}$ type zeolites was applied to pyrolyze kraft lignin to study the additive effect of different types of zeolite on pyrolysis. The pyrolysis oil yield and chemical structures were compared with the individual zeolite $\mathrm{Y}$ or $\mathrm{M}$ assisted pyrolysis of kraft lignin. A blank pyrolysis test (pyrolysis of kraft lignin without zeolite) was also conducted for comparisons. The goal of this work was to convert kraft lignin to low molecular weight aromatics (molecular weight is $\sim 100 \mathrm{~g} \cdot \mathrm{mol}^{-1}$ ) with low acidity through zeolite assisted pyrolysis, which could then be used as a precursor for bio-gasoline and/or bio-chemicals. To characterize the whole portions of various pyrolysis oils, we used $1 \mathrm{D}$ and 2D NMR and GPC to determine the structure of the pyrolysis oils. In addition, the thermal characteristics of the pyrolysis oil were analyzed by thermogravimetric analysis (TGA).

\section{Experimental section}

\section{Materials and methods}

All reagents used in this study were purchased from VWR International or Sigma-Aldrich (St. Louis, MO) and used as received. Lignin was isolated from a commercial USA softwood kraft pulping liquor. Zeolites (CBV 720 and CBV 21A) were purchased from Zeolyst, Inc.

\section{Lignin separation and purification}

Lignin samples used in this study were isolated from a commercial softwood kraft pulping liquor following published methods [20]. In brief, the cooking liquor was filtered through filter paper, and the filtrate was treated with ethylenediaminetetraacetic acid disodium salt (EDTA-2 $\mathrm{Na}^{+}$, $0.50 \mathrm{~g} / 100.00 \mathrm{~mL}$ liquor) and stirred for $1 \mathrm{~h}$. The liquor was adjusted to a pH value of 6.0 with $2.0 \mathrm{M} \mathrm{H}_{2} \mathrm{SO}_{4}$ and stirred vigorously for $1 \mathrm{~h}$. The liquors were then further acidified to a $\mathrm{pH}$ of 3.0 and frozen at $-20^{\circ} \mathrm{C}$. After thawing, the precipitates were collected on a medium sintered glass funnel and washed three times with cold water by suspending the precipitates in the water and stirring vigorously at $0^{\circ} \mathrm{C}$ for $1 \mathrm{~h}$. The precipitates were collected, air dried, and Soxhlet extracted with pentane for $24 \mathrm{~h}$. The solid product was air dried and further dried under high vacuum at $45^{\circ} \mathrm{C}$ for $48 \mathrm{~h}$. The resulting purified kraft lignin sample was stored at $-5^{\circ} \mathrm{C}$.

\section{Preparation of pyrolysis sample}

The pyrolysis samples containing kraft lignin (L) with a 1:1 weight ratio of zeolites were thoroughly mixed with stirring $[10,21]$. All the zeolites were pre-activated in a pyrolysis tube at $500^{\circ} \mathrm{C}$ under nitrogen for $6 \mathrm{~h}$. Different types of zeolites, including $\mathrm{Y}, \mathrm{M}$ and mixture of ' $\mathrm{Y}+\mathrm{M}$ ', were used as the additives in this work. A blank kraft lignin (L) was also prepared for pyrolysis comparison. The weight ratio of the mixture $\mathrm{Y}$ and $\mathrm{M}$ was 1:1. Detailed information of each zeolite used can be found in Table 1 [20].

\section{Equipment and process of pyrolysis}

Pyrolysis experiments were conducted in a quartz pyrolysis tube heated with a split-tube furnace [9]. Typically, the pyrolysis sample $(6.00 \mathrm{~g})$ was placed in a quartz sample boat that was then positioned in the center of a pre-heated pyrolysis tube. A K-type thermal couple was immersed in

Table $1 \mathrm{SiO}_{2} / \mathrm{Al}_{2} \mathrm{O}_{3}$ mole ratio, framework, code name used in this work and channel structure of each zeolite

\begin{tabular}{lll}
\hline & CBV720 & CBV21A \\
\hline $\mathrm{SiO}_{2} / \mathrm{Al}_{2} \mathrm{O}_{3}$ mole ratio & 30 & 20 \\
Framework & $\mathrm{FAU}$ & MOR \\
Code name & $\mathrm{Y}$ & $\mathrm{M}$ \\
Pore dimension & 3 & 1 \\
Pore size $(\AA)$ & $7.4 \times 7.4$ & $6.5 \times 7.0$ \\
\hline
\end{tabular}




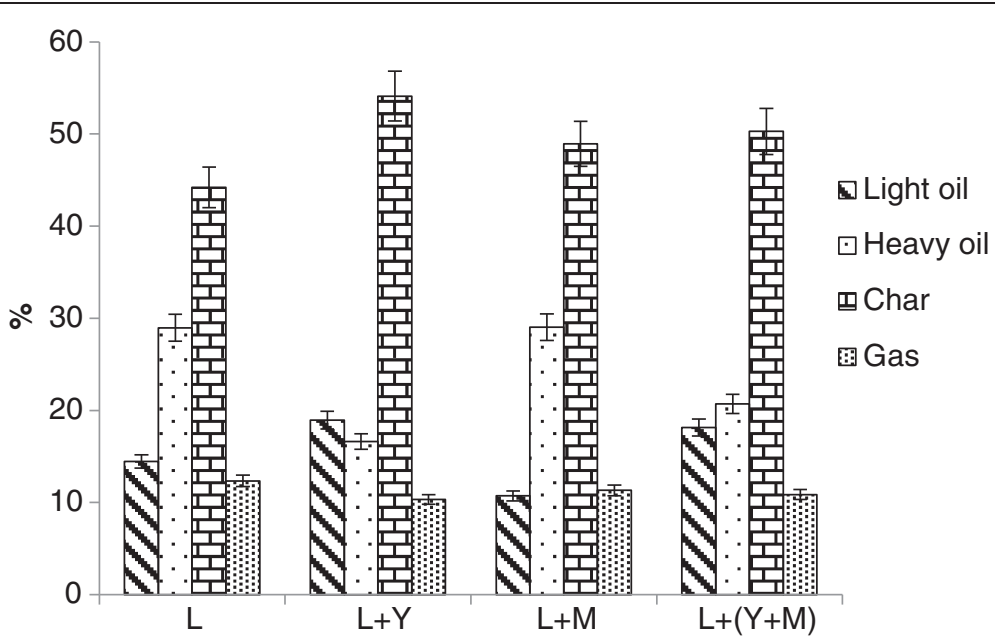

Figure 1 Yields (wt\%) of light oil, heavy oil, char (excludes the weight of zeolite) and gas for the pyrolysis of kraft lignin (L) and pyrolysis of kraft lignin with 1.0/1.0 ( $\left.W_{\text {additive }} / W_{\text {lignin }}\right)$ of $Y, M$, and ' $Y+M^{\prime}$ zeolites as additives at $600^{\circ} \mathrm{C}$ for $10 \mathrm{~min}$.

the sample powder during the pyrolysis to measure the heating rate. The pyrolysis tube was flushed with nitrogen gas, and the flow rate was adjusted to a value of $500 \mathrm{~mL} \mathrm{~min}^{-1}$ and then inserted in the pre-heated $\left(600^{\circ} \mathrm{C}\right)$ furnace. The outflow from pyrolysis was passed through two condensers, which were immersed in liquid $\mathrm{N}_{2}$. (Note: Liquid $\mathrm{N}_{2}$ was used for experimental convenience). Upon completion of pyrolysis ( 10 minutes), the reaction tube was removed from the furnace and allowed to cool to room temperature under constant $\mathrm{N}_{2}$ flow. The condensers were then removed from liquid nitrogen. The pyrolysis char and oil were collected for subsequent chemical analysis. In general, the liquid products contained two immiscible phases referred to as heavy and light oil. The light oil was acquired by decantation. The heavy oil was recovered by washing the reactor with acetone followed by evaporation under reduced pressure. Char yields were determined gravimetrically, and gas formation was calculated by mass difference.

\section{Characterization of pyrolysis oils by GPC}

The weight average molecular weights $\left(M_{w}\right)$ of the heavy oils were determined by Gel Permeation Chromatography analysis following literature methods [9]. Prior to GPC analysis, the heavy oil samples were dissolved in THF $\left(1 \mathrm{mg} \cdot \mathrm{mL}^{-1}\right)$ and filtered through a $0.45 \mu \mathrm{m}$ syringe filter. The samples were injected into a Polymer Standards Service (PSS) Security 1200 system featuring Agilent HighPerformance Liquid Chromatography (HPLC) vacuum degasser, isocratic pump, refractive index (RI) detector and UV detector $(270 \mathrm{~nm})$. Separation was achieved with four

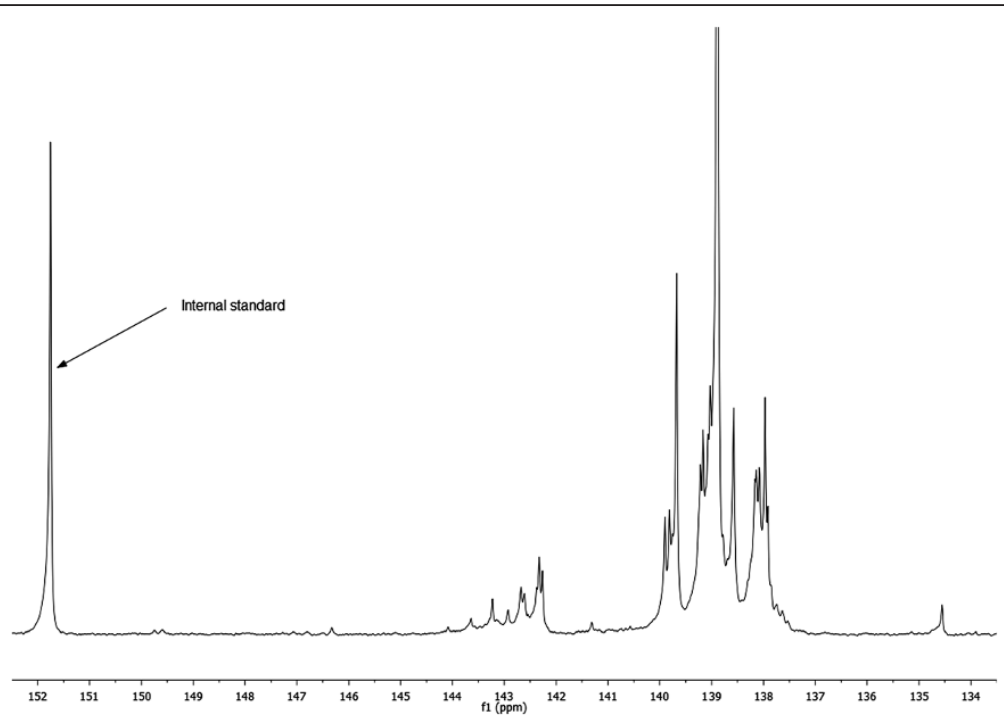

Figure $2{ }^{31} \mathrm{P}$ NMR spectra for the heavy oils produced by pyrolysis of kraft lignin. 
Table 2 Chemical shifts and integration regions for pyrolysis oil derivatized with TMDP in a quantitative ${ }^{31} \mathrm{P}$ NMR

\begin{tabular}{lll}
\hline Functional group & Integration region (ppm) \\
\hline $\begin{array}{l}\text { endo- } N \text {-hydroxy-5-norbornene-2, } \\
\text { 3-dicarboximide (NHND, internal standard) }\end{array}$ & $151.0-152.8$ \\
Aliphatic OH & $150.0-145.5$ \\
$\begin{array}{l}C_{5} \text { substituted guaiacyl } \\
\text { phenolic OH }\end{array}$ & $\beta-5$ & $144.7-142.8$ \\
& $4-\mathrm{O}-5$ & $142.8-141.7$ \\
Guaiacyl phenolic OH & $5-5$ & $141.7-140.2$ \\
Catechol type $\mathrm{OH}$ & $140.2-139.0$ \\
p-hydroxy-phenyl OH & & $139.0-138.2$ \\
Carboxylic acid-OH & $138.2-137.3$ \\
\hline
\end{tabular}

Waters Styragel columns (HR0.5, HR2, HR4, HR6) using tetrahydrofuran (THF) as the mobile phase $\left(1.0 \mathrm{~mL} \cdot \mathrm{min}^{-1}\right)$ with injection volumes of $25 \mu \mathrm{L}$. Data collection and processing were performed using PSS WinGPC Unity software. Molecular weights $\left(M_{w}\right)$ were calibrated against a calibration curve. The calibration curve was created by fitting a third order polynomial equation to the retention volumes obtained from a series of narrow molecular weight distribution polystyrene standards (i.e., $7.21 \times 10^{3}, 4.43 \times$ $\left.10^{3}, 1.39 \times 10^{3}, 5.80 \times 10^{2} \mathrm{Da}\right)$, dioctyl phthalate $\left(M_{w}=\right.$ $\left.390 \mathrm{~g} \cdot \mathrm{mol}^{-1}\right)$, 2,29-dihydroxy-4,49-dimethoxyl-benzophenone $\left(M_{w}=274 \mathrm{~g} \cdot \mathrm{mol}^{-1}\right)$, 2-phenylhydroquinone $\left(M_{w}=\right.$ $\left.186 \mathrm{~g} \cdot \mathrm{mol}^{-1}\right)$, phenol $\left(M_{w}=94 \mathrm{~g} \cdot \mathrm{mol}^{-1}\right)$ and acetone $\left(M_{w}=58 \mathrm{~g} \cdot \mathrm{mol}^{-1}\right)$. The curve fit had an $\mathrm{R}^{2}$ value of 0.998 .

\section{Characterization of pyrolysis oil by NMR Quantitative ${ }^{13} \mathrm{C} N \mathrm{NMR}$}

All NMR spectral data reported in this study were recorded with a Bruker Avance/DMX $400 \mathrm{MHz}$ NMR spectrometer.
Quantitative ${ }^{13} \mathrm{C}$ NMR were acquired using $100.0 \mathrm{mg}$ heavy oil dissolved in $450 \mu \mathrm{L}$ dimethyl sulfoxide- $d_{6}$ (DMSO- $d_{6}$ ) employing an inverse gated decoupling pulse sequence, $90^{\circ}$ pulse angle, a pulse delay of $20 \mathrm{~s}$ and 6000 scans at room temperature with a line-broadening (LB) of $5.0 \mathrm{~Hz}$. To reduce the measurement time, $1 \mathrm{mg} \cdot \mathrm{mL}^{-1}$ relaxation reagent chromium acetylacetonate was added into the solutions.

\section{Quantitative ${ }^{31} P$ NMR}

Quantitative ${ }^{31} \mathrm{P}$ NMR were acquired after in situ derivatization of the samples using $10.0 \mathrm{mg}$ of heavy oil with 2chloro-4,4,5,5-tetramethyl-1,3,2-dioxaphospholane (TMDP) in a solution of $(1.6: 1 \mathrm{v} / \mathrm{v})$ pyridine $/ \mathrm{CDCl}_{3}$, chromium acetylacetonate (relaxation agent) and endo- $\mathrm{N}$-hydroxy-5norbornene-2, 3-dicarboximide (NHND, internal standard). ${ }^{31} \mathrm{P}$ NMR spectra data was acquired using an inverse gated decoupling pulse sequence, $90^{\circ}$ pulse angle, $25 \mathrm{~s}$ pulse delay, and 128 scans at room temperature with a LB of $4.0 \mathrm{~Hz}$.

\section{Characterization of Pyrolysis Oil by HSQC-NMR}

The sample used for HSQC-NMR was the same as ${ }^{13} \mathrm{C}$ NMR. HSQC-NMR were acquired employing a standard Bruker pulse sequence "hsqcetgpsi.2" with a $90^{\circ}$ pulse, $0.11 \mathrm{~s}$ acquisition time, a $1.5 \mathrm{~s}$ pulse delay, a ${ }^{1} \mathrm{~J}_{\mathrm{C}-\mathrm{H}}$ of $145 \mathrm{~Hz}, 48$ scans and acquisition of 1024 data points $\left(\right.$ for ${ }^{1} \mathrm{H}$ ) and 256 increments (for ${ }^{13} \mathrm{C}$ ). The ${ }^{1} \mathrm{H}$ and ${ }^{13} \mathrm{C}$ pulse widths are $\mathrm{p} 1=$ $11.30 \mu$ s and $\mathrm{p} 3=10.00 \mu \mathrm{s}$, respectively. The ${ }^{1} \mathrm{H}$ and ${ }^{13} \mathrm{C}$ spectral widths are $13.02 \mathrm{ppm}$ and $220.00 \mathrm{ppm}$, respectively. The central solvent peak was used for chemical shift calibration. HSQC data processing and plots were carried out using MestReNova v7.1.0 software's default processing template and automatic phase and baseline correction.

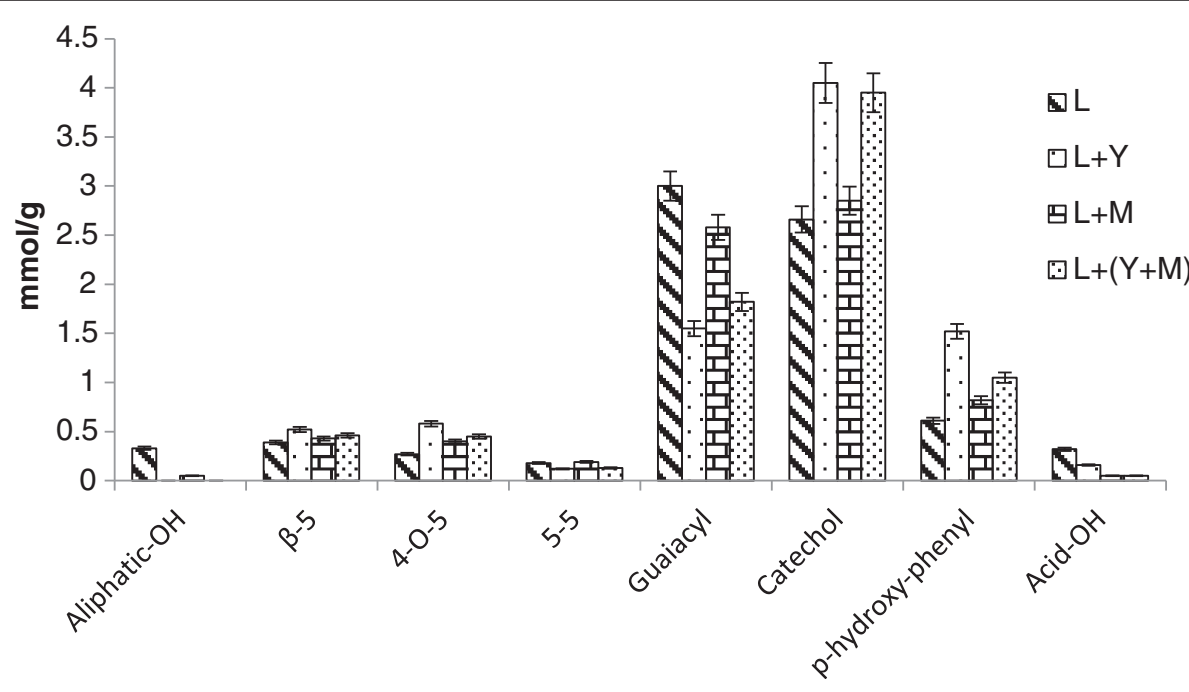

Figure 3 Hydroxyl group contents of different heavy oils produced by pyrolysis of kraft lignin. 


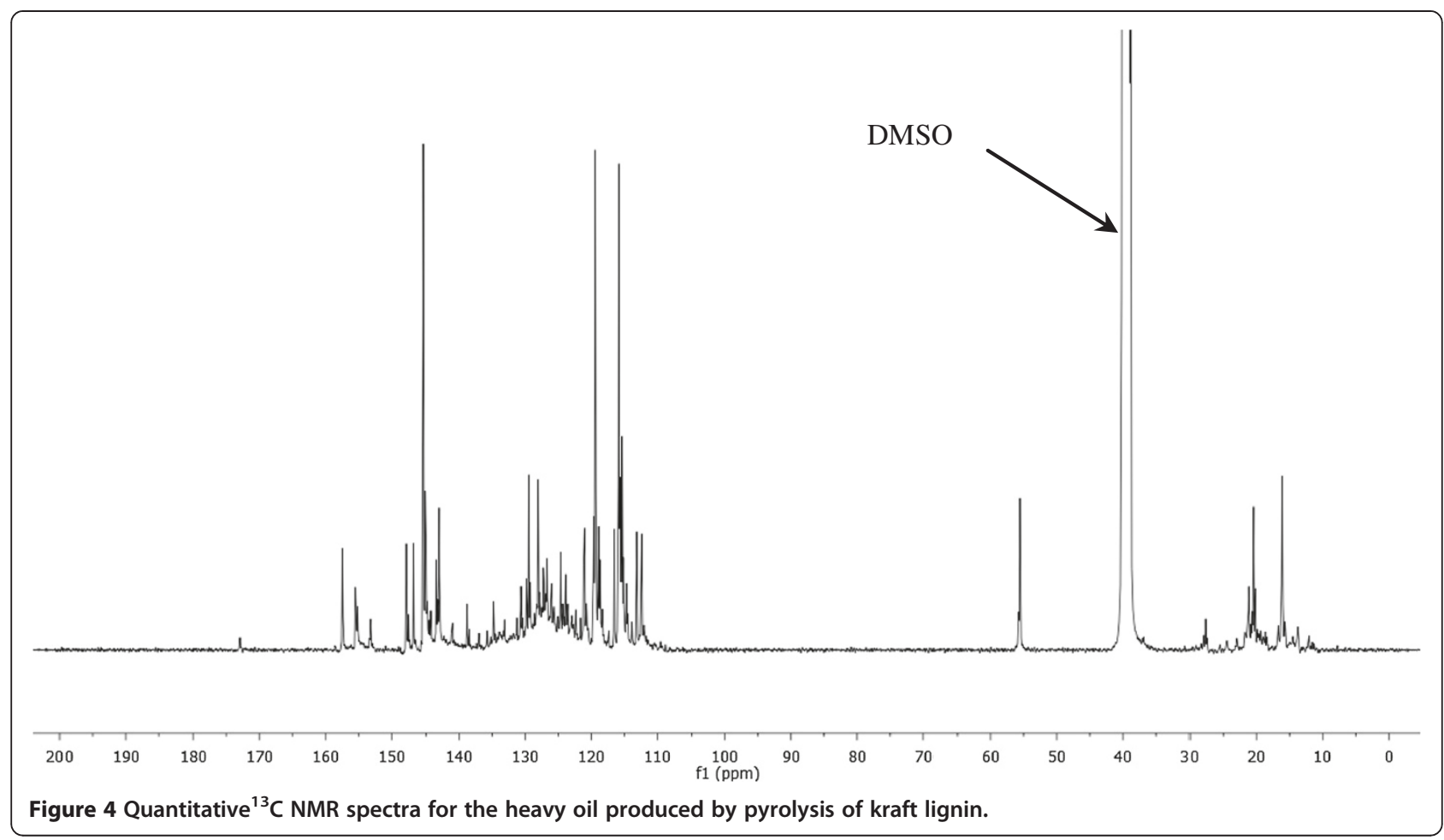

\section{Thermogravimetric analysis (TGA) of pyrolysis oil}

The thermogravimetric analysis (TGA) of the pyrolysis oil was performed on Q50 TGA (TA Instruments, USA). About $10 \mathrm{mg}$ of sample for this analysis was used and heated from room temperature to $600^{\circ} \mathrm{C}$ at the rate of $10^{\circ} \mathrm{C} / \mathrm{min}$ under the flow of $\mathrm{N}_{2}$ at the rate of $60 \mathrm{~mL} / \mathrm{min}$.

\section{Statistical analysis}

Triplicate tests were conducted for all the pyrolysis experiments, and a mean value was reported for the characterization measurement. The standard deviations were marked in all the quantitative analysis figures.

\section{Results and discussion}

\section{Pyrolysis yields analysis}

The lignin pyrolysis products are in gas, liquid, and solid form. Carbon monoxide, carbon dioxide and methane are the most abundant components in the gas phase of pyrolysis of lignin. The solid form products are mainly recognized as char with high energy [22]. However, it is not a preferred as the liquid product. The liquid product consists of light and heavy oil. The light oil contains nearly $80 \% \mathrm{w} / \mathrm{w}$ water and another $10 \% \mathrm{w} / \mathrm{w}$ is methanol, catechol, and acetic acid [23]. The heavy oils are dark brown liquids, which are comprised of hundreds of highly oxygenated organic compounds [22]. As the principle pyrolysis products, they could be used as precursors of bio-fuels and bio-chemicals,

Table $3{ }^{13} \mathrm{C}$ NMR chemical shift assignment range of lignin pyrolysis oil based on the chemical shift database created in our previous work

\begin{tabular}{|c|c|c|}
\hline \multicolumn{2}{|l|}{ Functional group } & Integration region (ppm) \\
\hline \multicolumn{2}{|c|}{ Carbonyl or Carboxyl bond } & $215.0-166.5$ \\
\hline \multicolumn{2}{|l|}{ Aromatic C-O bond } & $166.5-142.0$ \\
\hline \multicolumn{2}{|l|}{ Aromatic C-C bond } & $142.0-125.0$ \\
\hline \multicolumn{2}{|l|}{ Aromatic $\mathrm{C}-\mathrm{H}$ bond } & $125.0-95.8$ \\
\hline \multicolumn{2}{|l|}{ Aliphatic C-O bond } & $95.8-60.8$ \\
\hline \multicolumn{2}{|c|}{ Methoxyl-Aromatic bond } & $60.8-55.2$ \\
\hline & General & $55.2-0.0$ \\
\hline \multirow[t]{2}{*}{ Aliphatic C-C bond } & Methyl - Aromatic $\left(\mathrm{CH}_{3}-\mathrm{Ar}\right)$ & $21.6-19.1$ \\
\hline & Methyl - Aromatic at ortho position of a hydroxyl or methoxyl group $\left(\mathrm{CH}_{3}-\mathrm{Ar}^{\prime}\right)$ & $16.1-15.4$ \\
\hline
\end{tabular}




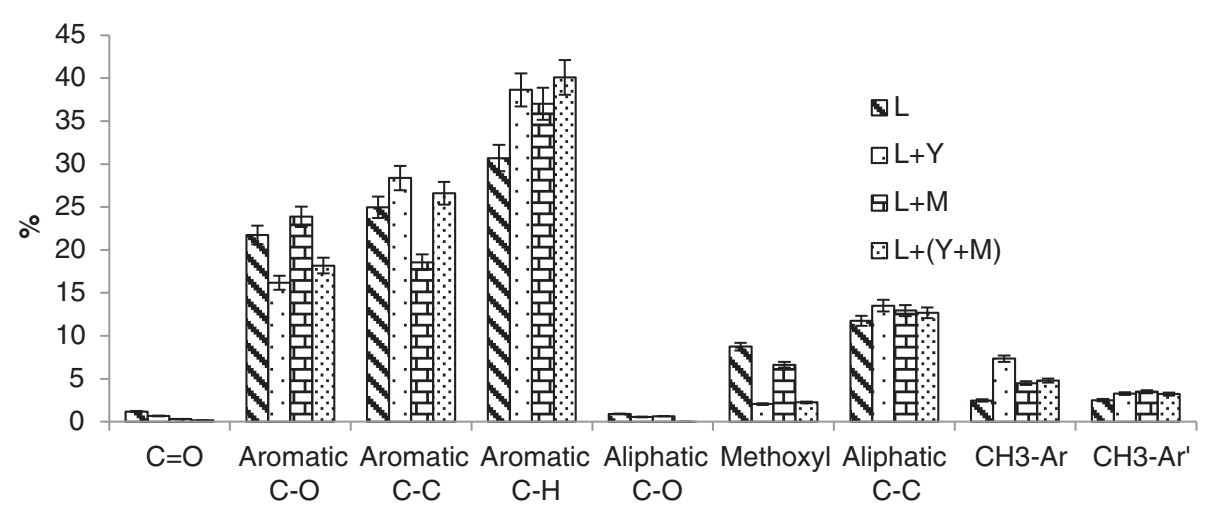

Figure 5 Quantitative ${ }^{13} \mathrm{C}$ NMR integration results for heavy oils produced from kraft lignin. The results are shown as the percentage of total carbon.

therefore the heavy oils are desirable to obtain. Figure 1 shows the pyrolysis yields of different products, including light oil, heavy oil, gas and char from different kraft lignin samples. Compared with the blank lignin sample, the additive zeolite Y could increase the productions of light oil and char by $31.0 \%$ and $22.4 \%$, respectively, but decreased the production of heavy oil by $42.6 \%$. The addition of zeolite $\mathrm{M}$ to lignin prior to pyrolysis was found to increase the productions of heavy oil and char by $10.7 \%$ and $2.0 \%$, respectively, but decrease the production of light oil by $25.9 \%$ in comparison with the blank sample. The product amounts (light oil, heavy oil and char) from the zeolite mixture ' $\mathrm{Y}+\mathrm{M}$ ' catalyzed pyrolysis lie between the individual zeolite $\mathrm{Y}$ and $\mathrm{M}$ catalyzed pyrolysis. In addition, for all the pyrolysis studies, there was no significant difference in gas production. It should be noted that the significant amount of char was formed during the pyrolysis of kraft lignin, which might bring plugging issues and

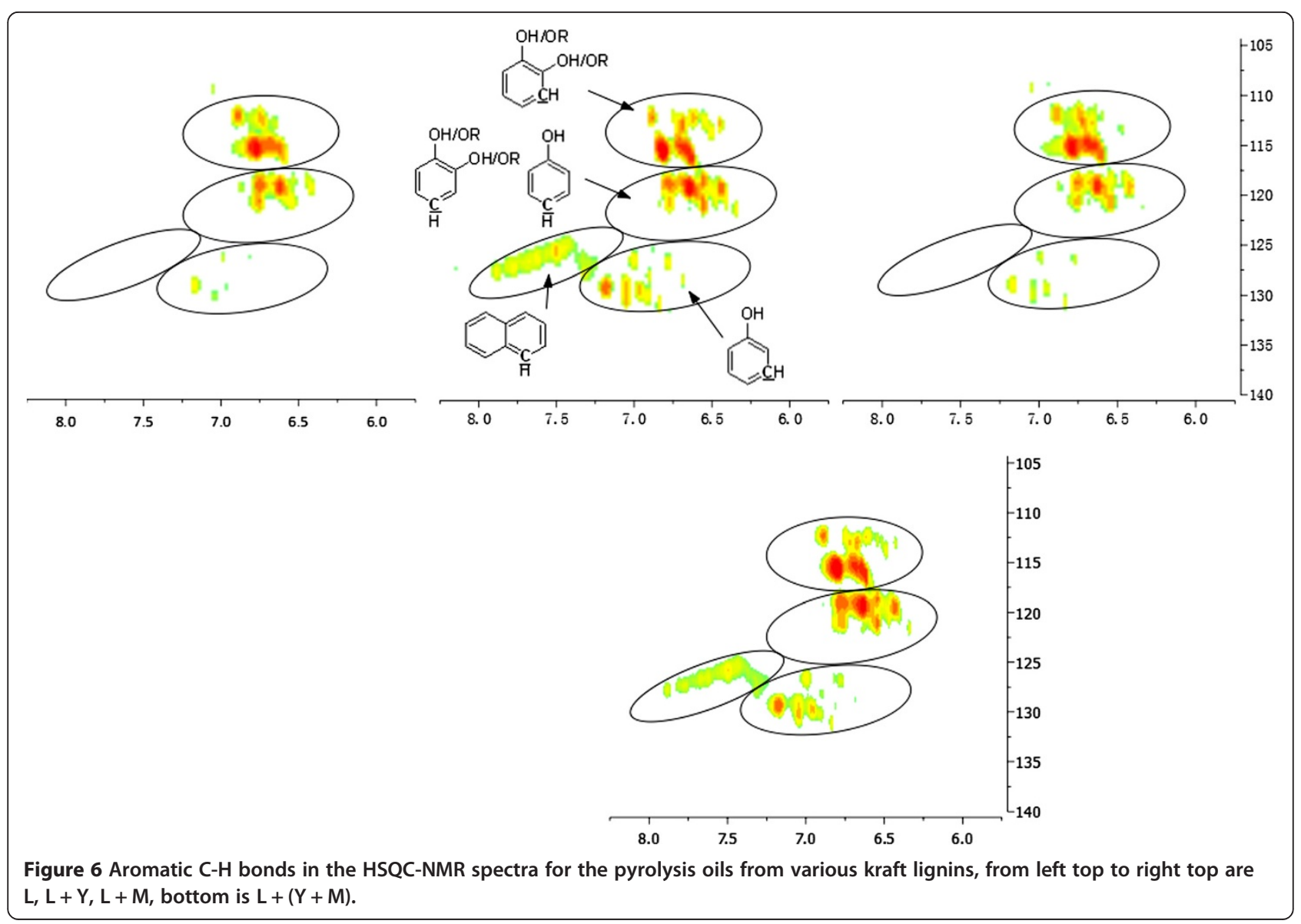


loss of fluidization in fluidized bed reactors of the continuous reactor systems.

\section{Quantitative ${ }^{31} \mathrm{P}$ NMR analysis of pyrolysis oil}

Our previous work introduced quantitative ${ }^{31} \mathrm{P}$ NMR to determine hydroxyl functional groups in pyrolysis oils [10]. The ${ }^{31} \mathrm{P}$ NMR spectrum, chemical shifts and integration regions of the phosphitylated bio-oils with 2-chloro-4, 4, 5, 5-tetramethyl-1, 3, 2-dioxaphospholane (TMDP) are summarized in Figure 2 and Table 2 [10].

After the use of Y zeolite as an additive, the aliphatic hydroxyl groups in the heavy oils were completely decomposed. With the $\mathrm{M}$ type zeolite, the aliphatic hydroxyl groups were decreased by $84.8 \%$. The results (Figure 3 ) show that for the zeolites studied the resulting pyrolysis oils were significantly dehydrated. Compared to the $\mathrm{M}$ zeolites, after the use of Y zeolite, the heavy oils contained more C5 substituted guaiacyl phenolic, catechol and $p$-hydroxyphenyl types of hydroxyl groups but less normal guaiacyl phenolic hydroxyl group. In contrast, with the addition of $\mathrm{M}$ zeolite, lignin pyrolysis yielded more guaiacyl phenolics but less $p$-hydroxy-phenyl and C5 substituted guaiacyl phenolic types of hydroxyl groups. Since the catechol and $p$-hydroxyphenyl types of hydroxyl groups are the decomposition products of methoxyl-aromatic linkage and ether bonds in the lignin structure, this indicates that the $\mathrm{Y}$ zeolite could perform the cleavage of aromatic $\mathrm{C}-\mathrm{O}$ bonds more effectively. After the use of zeolites, the content of carboxylic acid decreased by $50.0 \%$ and $84.3 \%$ for the $\mathrm{Y}$ and $\mathrm{M}$ zeolites, respectively. This result indicates that the $M$ zeolites could induce decarboxylation reactions more efficiently than $\mathrm{Y}$ zeolite. The mixture of ' $\mathrm{Y}+\mathrm{M}$ ' could completely decompose the aliphatic hydroxyl groups, which is similar to individual $\mathrm{Y}$ zeolite. Interestingly, the mixture of ' $\mathrm{Y}+\mathrm{M}$ ' could also significantly decrease the carboxyl groups by $84.2 \%$, which is similar to the effect of individual $\mathrm{M}$ zeolite. The yields of other hydroxyl groups in the zeolite mixture ' $\mathrm{Y}+\mathrm{M}$ ' catalyzed bio-oil were between the individual $\mathrm{Y}$ and $\mathrm{M}$ zeolite catalyzed bio-oils. These results show that the mixture of ' $\mathrm{Y}+\mathrm{M}$ ' manifests the dual characteristics, which combine the catalytic effects of $\mathrm{Y}$ and $\mathrm{M}$.

\section{Quantitative ${ }^{13} \mathrm{C}$ NMR analysis of pyrolysis oil}

To fully characterize the functional groups in the heavy oils, a detailed analysis was accomplished by using ${ }^{13} \mathrm{C}$ NMR. Figure 4 shows the ${ }^{13} \mathrm{C}$ NMR spectrum of pyrolysis heavy oil. The ${ }^{13} \mathrm{C}$ NMR chemical shift assignment ranges are based on our previous work and shown in the Table 3 [9].

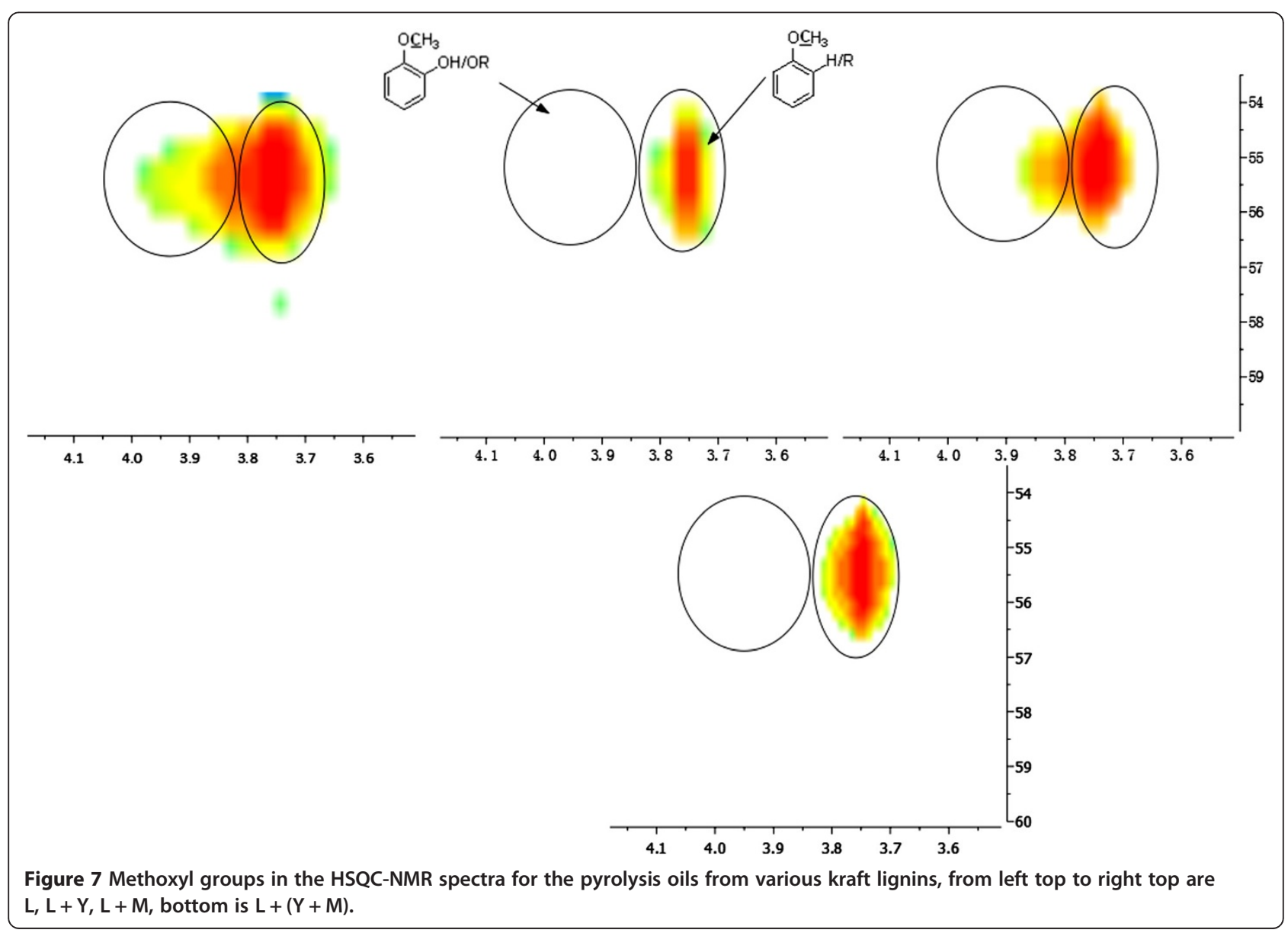


The integration results of this analysis for the heavy oils are summarized in Figure 5. After the use of Y zeolite, the heavy oils contained $76.4 \%$ less methoxyl groups than the blank pyrolysis oil, which indicates a very efficient decomposition of methoxyl groups and this result could explain the increasing contents of catechol type and $p$-hydroxyphenyl type hydroxyl groups detected by ${ }^{31} \mathrm{P}$ NMR. The two types of methyl aromatic bonds (methyl-Ar groups with and without a hydroxyl or ether group in the ortho position) in the heavy oils are reported to be the rearrangement products of methoxyl groups [24]. After the use of Y or $\mathrm{M}$ zeolites, the heavy oils contained relatively large amount of methyl aromatic bonds, which is the evidence for the enhanced cleavage of methoxyl groups. The ${ }^{13} \mathrm{C}$ NMR results also show that there were only $43.7 \%$ carboxyl groups remaining in the pyrolysis oil produced with $\mathrm{Y}$ zeolite, which is consistent with ${ }^{31} \mathrm{P}$ NMR results (acid-OH contents in Figure 3). With the use of $\mathrm{M}$ zeolite, the heavy oils contained relatively large amounts of aromatic $\mathrm{C}-\mathrm{O}$ bond but lesser amounts of aromatic $\mathrm{C}-\mathrm{C}$ bonds, which indicate that $\mathrm{Y}$ zeolite prefers to cleave aromatic $\mathrm{C}-\mathrm{C}$ bonds or prevent the formation of such bonds. For the $\mathrm{Y}$ zeolite upgraded pyrolysis oils, the contents of oxygen substituents including aromatic $\mathrm{C}-\mathrm{O}$ and aliphatic $\mathrm{C}-\mathrm{O}$ bonds, carbonyl and methoxyl groups decreased by more than $40 \%$. In addition, almost all the remaining oxygen functionality (up to $\sim 85 \%$ ) in Y zeolite upgraded pyrolysis oils belongs to the phenolic hydroxyl groups. The amounts of functional groups in the ' $\mathrm{Y}+\mathrm{M}$ ' updated pyrolysis oil are between the individual $\mathrm{Y}$ and $\mathrm{M}$ updated oils, which is comparable to the results of the ${ }^{31}$ P NMR analysis.

\section{HSQC-NMR analysis of pyrolysis oil}

In the ${ }^{13} \mathrm{C}$ NMR analysis, due to the extremely complicated components in the pyrolysis oils, the overlaps of different functional groups will be inevitable, which will bring unknown effects for the quantitative characterization of pyrolysis oils by ${ }^{13} \mathrm{C}$ NMR. However, the limitations of ${ }^{13} \mathrm{C}$ NMR can be addressed using modern 2D NMR (such as HSQC-NMR) techniques, which has been developed to semi-quantitatively analyze over 30 different $\mathrm{C}$ - $\mathrm{H}$ bonds in the pyrolysis oils [24-27]. We have previously shown that HSQC-NMR was uniquely well suited to analyze various $\mathrm{C}-\mathrm{H}$ bonds present in the pyrolysis oils. The HSQC-NMR spectra for the pyrolysis oils after the use of zeolites are shown in Figures 6, 7 and 8. HSQC-NMR results show that after the use of Y zeolite, the pyrolysis oils contained some polyaromatic hydrocarbons (PAH). In contrast, there are

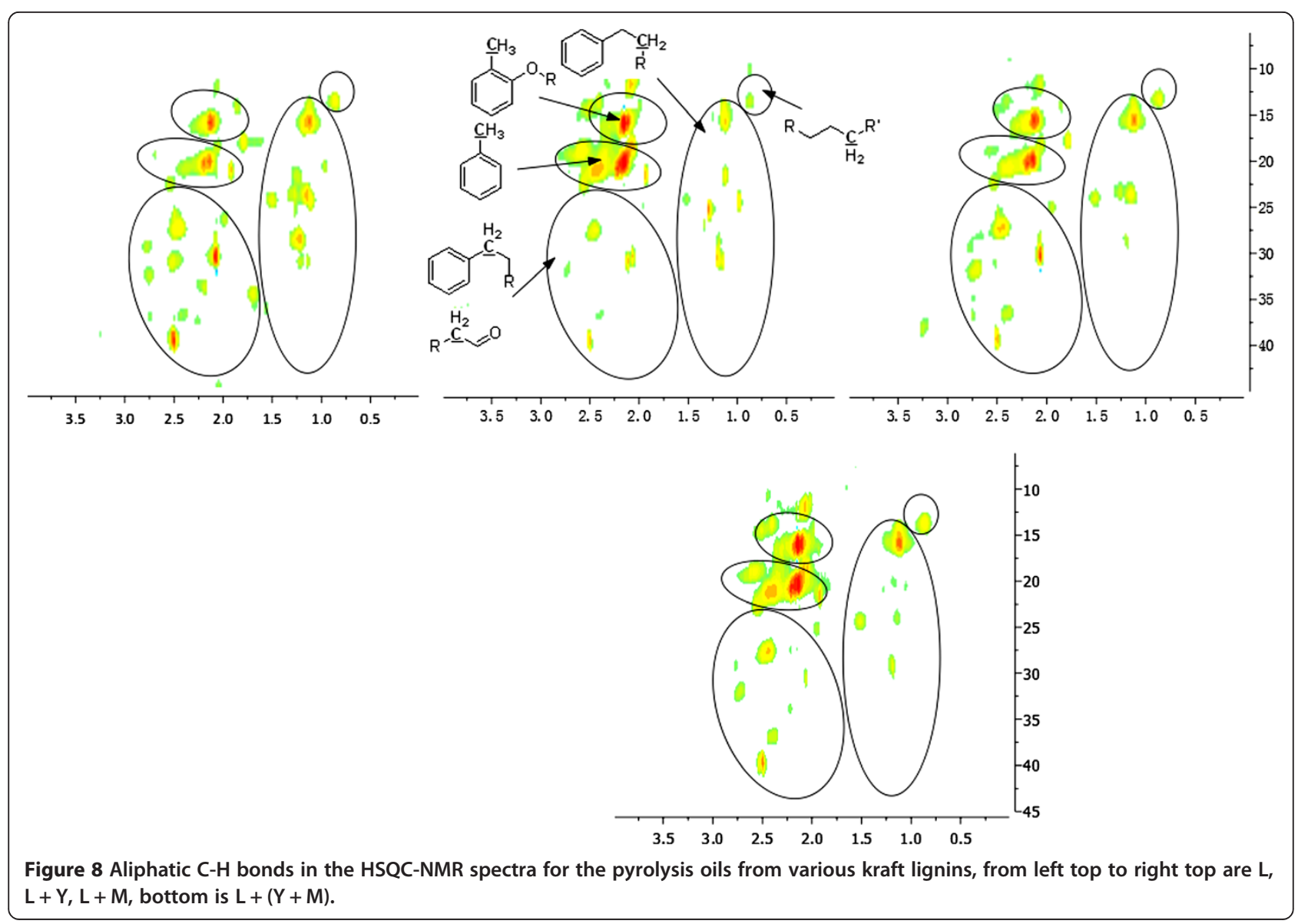




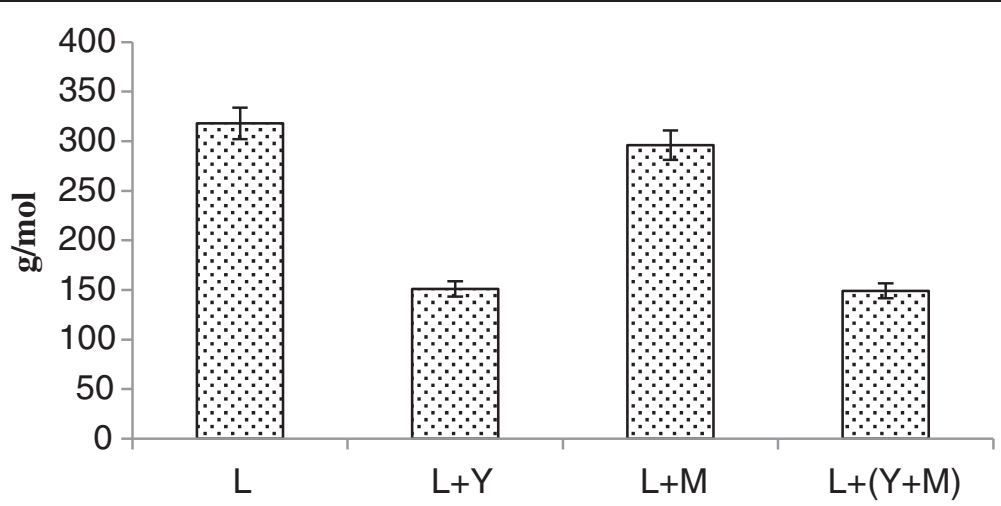

Figure 9 Molecular weight distributions $\left(M_{w}\right)$ of heavy oils produced by pyrolysis of kraft lignin.

almost no PAH in M zeolites upgraded pyrolysis oils and in the blank pyrolysis oil. The native methoxyl groups in lignin (with a hydroxyl group or ether bond in the ortho position) were completely eliminated after adding $\mathrm{Y}$ zeolite during the pyrolysis. For the $\mathrm{M}$ zeolite catalyzed pyrolysis samples, the decomposition of native type of methoxyl group in lignin were also improved. The content of rearranged methoxyl groups (no hydroxyl group or ether bond in the ortho position) also decreased after the use of Y zeolite, which is consisted with the significant reduced amount of methoxyl groups detected by ${ }^{13} \mathrm{C}$ NMR. Compared to the rearranged methoxyl groups, the zeolites prefer to cleave the native methoxyl groups, which may due to the hydroxyl group in the ortho position that facilitates the cleavage. After the use of zeolites, there were much more methyl aromatic bonds in the pyrolysis oil which is consistent with our ${ }^{13} \mathrm{C}$ NMR result. With respect to the control pyrolysis oil, the catalyzed pyrolysis oils have relatively lower amounts of long chain aliphatic bonds. The addition of zeolite during pyrolysis has been reported to improve the cleavage of aliphatic $\mathrm{C}-\mathrm{C}$ bonds in the model compounds, which could explain the reduced contents of such bonds in the catalyzed pyrolysis oils. Compared with the individual $\mathrm{Y}$ and $\mathrm{M}$ zeolite catalyzed pyrolysis oil, the effect of zeolite mixture ' $\mathrm{Y}+\mathrm{M}$ ' on the pyrolysis is between the $\mathrm{Y}$ and $\mathrm{M}$ zeolite, especially in the aromatic $\mathrm{C}-\mathrm{H}$ bonds, methoxyl groups and aliphatic $\mathrm{C}-\mathrm{H}$ bonds.

\section{Molecular weight analysis of pyrolysis oil}

The weight average molecular weights $\left(M_{w}\right)$ for the heavy oils produced by pyrolysis of kraft lignin with zeolites at $600^{\circ} \mathrm{C}$ are summarized in Figure 9. The addition of zeolite $\mathrm{Y}$ was found to decrease the $M_{w}$ of pyrolysis oil by $56 \%$ and the addition of zeolite $M$ could decrease the $M_{w}$ of pyrolysis oil only by $7 \%$. The addition of mixture of zeolite ' $\mathrm{Y}+\mathrm{M}$ ' decreased the $M_{w}$ of pyrolysis oil by $55 \%$. This analysis indicates the molecular weight decreased to the gasoline range $\left(80-120 \mathrm{~g} \mathrm{~mol}^{-1}\right)$ after the use of $\mathrm{Y}$ zeolites. The molecular weight of zeolite mixture ' $\mathrm{Y}+\mathrm{M}$ ' catalyzed pyrolysis oil was similar to the individual zeolite $\mathrm{Y}$ assisted pyrolysis.

\section{TGA analysis of pyrolysis oil}

The thermogravimetric analysis (TGA) profile of the pyrolysis oils was shown in Figure 10. From the figure, it can be clearly seen that the weight loss of the pyrolysis oils

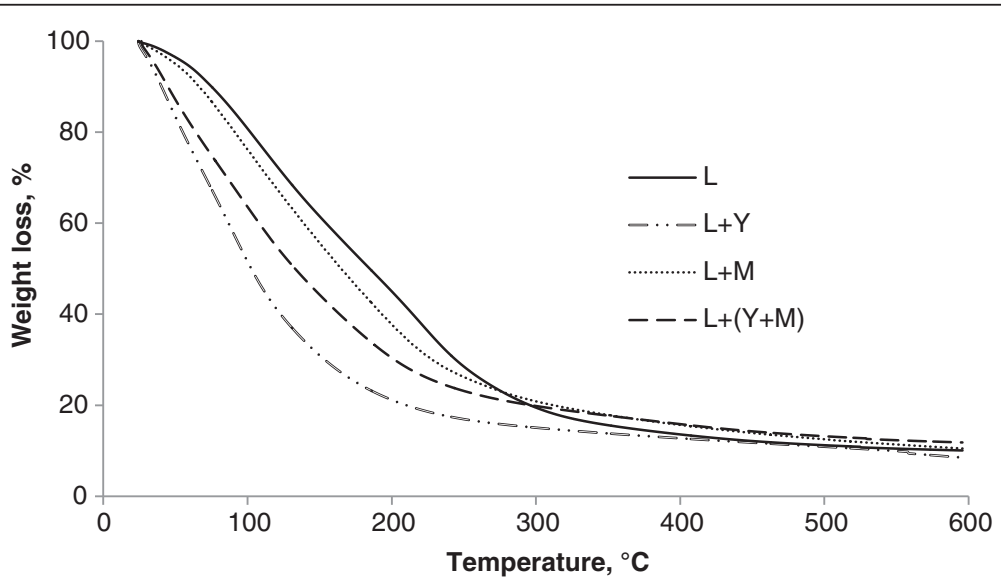

Figure 10 TGA profile of pyrolysis oil under nitrogen atmosphere. 
increases rapidly during the temperature range $80-300^{\circ} \mathrm{C}$, which was attributed to the formation of volatile hydrocarbons. For all the pyrolysis oils, about $80 \%$ of weight loss was in this range. These values were similar to reported results [28]. During the temperature range $300-600^{\circ} \mathrm{C}$, the weight loss was small. This signified the formation of char during this stage since the char could neither be physically evaporated nor thermally cracked at $600^{\circ} \mathrm{C}$ [29].

The effect of zeolite on the lignin pyrolysis was also reflected on the bio-oil TGA profiles. For example, during the temperature range $80-300^{\circ} \mathrm{C}$, the rate of weight loss was highest in $\mathrm{Y}$ zeolite catalyzed bio-oil, followed by the $\mathrm{M}$ zeolite catalyzed bio-oil and the non-catalyzed bio-oil (L) that has the lowest rate. The TGA weight loss rate of zeolite mixture ' $\mathrm{Y}+\mathrm{M}$ ' catalyzed bio-oil was between the bio-oils generated from $\mathrm{Y}$ and $\mathrm{M}$ assisted pyrolysis. These findings were in good agreement with the molecular weight analysis of the bio-oils: the bio-oils with lower molecular weight generally decomposed faster than the higher molecular weight samples in the TGA analysis.

\section{Conclusions}

The mixture of $\mathrm{Y}$ and $\mathrm{M}$ type zeolites was applied to pyrolyze kraft lignin, aiming to study the combination effect of different types of zeolite on pyrolysis. The product yields (light oil, heavy oil and char) from the zeolite mixture ' $\mathrm{Y}+$ M' catalyzed pyrolysis lie between the individual pyrolysis with zeolite $\mathrm{Y}$ and $\mathrm{M}$. The NMR analysis revealed that the yields of hydroxyl groups and other functional groups in the bio-oils acquired from the zeolites mixture ' $\mathrm{Y}+\mathrm{M}$ ' catalyzed pyrolysis were between individual $\mathrm{Y}$ and $\mathrm{M}$ zeolites assisted pyrolysis. The molecular weight of zeolite mixture ' $\mathrm{Y}+\mathrm{M}$ ' catalyzed pyrolysis oil was similar to the individual zeolite $\mathrm{Y}$ assisted pyrolysis. These results show that the mixture of ' $Y+M$ ' manifests the dual characteristics, which combine the catalytic effects of $\mathrm{Y}$ and $\mathrm{M}$, such as the cleavage of methoxyl-aromatic and ether bonds as well as the decompose of the carboxyl groups in a biooil. The significantly decreased molecular weight and acidity present a more suitable precursor for biogasoline and bio-chemicals.

\section{Competing interests}

The authors declare that they have no competing interests.

\section{Authors' contributions}

This research paper was written in a collaborative, team manner, hence it was jointly prepared by FH, HB, SP, YP and AR. All authors read and approved the final manuscript.

\section{Acknowledgements}

The authors thank the US Department of Energy (DOE) for providing financial support (project: DE-EE0003144) for these studies.

Received: 11 November 2013 Accepted: 4 March 2014

Published: 14 March 2014

\section{References}

1. Demirbas A: Progress and Recent Trends in Biofuels. Prog Energy Combust Sci 2007, 33(1):1-18

2. Ragauskas AJ, Williams CK, Davison BH, Britovsek G, Cairney J, Eckert CA, Frederick WJ Jr, Hallett JP, Leak DJ, Liotta CL, Mielenz JR, Murphy R, Templer R, Tschaplinski T: The path forward for biofuels and biomaterials. Science 2006, 311(5760):484-489

3. David K, Ragauskas AJ: Switchgrass as an energy crop for biofuel production: a review of its lignocellulosic chemical properties. Energy \& Environ Sci 2010, 3(9):1182-1190.

4. Zakzeski J, Bruijnincx PC, Jongerius AL, Weckhuysen BM: The catalytic valorization of lignin for the production of renewable chemicals. Chem Rev 2010, 110(6):3552-3599.

5. Pu Y, Zhang D, Singh PM, Ragauskas AJ: The new forestry biofuels sector Biofuels Bioprod Biorefin 2008, 2(1):58-73.

6. Hallac BB, Ragauskas AJ: Analyzing cellulose degree of polymerization and its relevancy to cellulosic ethanol. Biofuels Bioprod Biorefin 2011, 5(2):215-225.

7. Kleinert M, Barth T: Phenols from lignin. Chemical Engineering \& Tech 2008, 31(5):736-745

8. Nagy M, Kosa M, Theliander $\mathrm{H}$, Ragauskas AJ: Characterization of $\mathrm{CO}_{2}$ precipitated Kraft lignin to promote its utilization. Green Chem 2010 12(1):31-34

9. Ben $H$, Ragauskas AJ: NMR characterization of pyrolysis oils from kraft lignin. Energy Fuel 2011, 25(5):2322-2332.

10. Ben H, Ragauskas AJ: Pyrolysis of Kraft lignin with additives. Energy Fuel 2011, 25(10):4662-4668.

11. Gellerstedt G, Li J, Eide I, Kleinert M, Barth T: Chemical structures present in biofuel obtained from lignin. Energy Fuel 2008, 6:4240-4244.

12. Ingram L, Mohan D, Bricka M, Steele P, Strobel D, Crocker D, Mitchell B, Mohammad J, Cantrell K, Pittman CU Jr: Pyrolysis of wood and bark in an auger reactor: physical properties and chemical analysis of the produced bio-oils. Energy Fuel 2007, 22(1):614-625.

13. Mullen CA, Strahan GD, Boateng AA: Characterization of various fast-pyrolysis bio-oils by NMR spectroscopy. Energy \& Fuels 2009, 23(5):2707-2718.

14. Beis SH, Mukkamala S, Hill N, Joseph J, Baker C, Jensen B, Stemmler EA, Wheeler MC, Frederick BG, Heiningen AV, Berg AG, DeSisto WJ: Fast pyrolysis of lignins. BioResources 2010, 5(3):1408-1424.

15. Huber GW, Iborra S, Corma A: Synthesis of transportation fuels from biomass: chemistry, catalysts, and engineering. Chem Rev 2006, 106(9):4044-4098.

16. Czernik S, Bridgwater AV: Overview of applications of biomass fast pyrolysis oil. Energy Fuel 2004, 18(2):590-598.

17. Mullen CA, Boateng AA: Catalytic pyrolysis-GC/MS of lignin from several sources. Fuel Process Technol 2010, 91(11):1446-1458.

18. French $\mathrm{R}$, Czernik S: Catalytic pyrolysis of biomass for biofuels production. Fuel Process Technol 2010, 91(1):25-32

19. Zhao Y, Deng L, Liao B, Fu Y, Guo QX: Aromatics production via catalytic pyrolysis of pyrolytic lignins from bio-oil. Energy Fuel 2010, 24(10):5735-5740.

20. Ben H, Ragauskas AJ: One step thermal conversion of lignin to the gasoline range liquid products by using zeolites as additives. RSC Advances 2012, 2(33):12892-12898.

21. Ben $\mathrm{H}$, Ragauskas AJ: Influence of $\mathrm{Si} / \mathrm{Al}$ ratio of ZSM-5 zeolite on the properties of lignin pyrolysis products. ACS Sustainable Chemistry and Engineering 2013, 1:316-324.

22. Mohan D, Pittman CU, Steele PH: Pyrolysis of wood/biomass for bio-oil: a critical review. Energy Fuel 2006, 20(3):848-889.

23. Mu W, Ben H, Ragauskas A, Deng Y: Lignin pyrolysis components and upgrading-technology review. BioEnergy Res 2013, 6:1183-1204.

24. Ben H, Ragauskas AJ: Heteronuclear single-quantum correlation-nuclear magnetic resonance (HSQC-NMR) fingerprint analysis of pyrolysis oils. Energy Fuel 2011, 25(12):5791-5801.

25. Samuel R, Pu Y, Raman B, Ragauskas AJ: Structural characterization and comparison of switchgrass ball-milled lignin before and after dilute acid pretreatment. Appl Biochem Biotechnol 2009, 162(1):62-74.

26. Salanti A, Zoia L, Orlandi M, Zanini F, Elegir G: Structural characterization and antioxidant activity evaluation of lignins from rice husk. J of Agric of Food and Chem 2010, 58(18):10049-10055.

27. Qu C, Kishimoto T, Kishino M, Hamada M, Nakajima N: Heteronuclear single-quantum coherence nuclear magnetic resonance (HSQC NMR) characterization of acetylated fir (Abies sachallnensis MAST) wood regenerated from ionic liquid. J of Agricul of Food and Chem 2011, 59(10):5382-5389. 
28. Mourant D, Wang Z, He M, Wang XS, Garcia-Perez M, Ling K, Li CZ: Mallee wood fast pyrolysis: effects of alkali and alkaline earth metallic species on the yield and composition of bio-oil. Fuel 2011, 90(9):2915-2922.

29. Asadullah M, Rahman MA, Ali MM, Rahman MS, Motin MA, Sultan MB, Alam MR: Production of bio-oil from fixed bed pyrolysis of bagasse. Fuel 2007, 86(16):2514-2520.

doi:10.1186/2043-7129-2-7

Cite this article as: Huang et al:: The use of combination of zeolites to pursue integrated refined pyrolysis oil from kraft lignin. Sustainable Chemical Processes 2014 2:7.

\section{Publish with ChemistryCentral and every scientist can read your work free of charge \\ "Open access provides opportunities to our colleagues in other parts of the globe, by allowing anyone to view the content free of charge." \\ W. Jeffery Hurst, The Hershey Company. \\ - available free of charge to the entire scientific community \\ - peer reviewed and published immediately upon acceptance \\ - cited in PubMed and archived on PubMed Central \\ - yours - you keep the copyright

